\title{
Study on Building E-Commerce Brand of Agricultural Produce
}

\author{
Yun-Duan Chen \\ Hubei Three Gorges Polytechnic, YICHANG, HUBEI, CHINA \\ Emai:250386554@qq.com
}

\begin{abstract}
This Paper, specific to the current plight that many e-Businesses of agricultural produce is short of profitability and difficult to survive, has proposed countermeasures of establishing brand awareness, designing brand image, focusing on user's emotional experience, incorporating new business model and so on to boost the building of e-Business brand of agricultural produce, and thereby to improve the competitiveness of e-Business brand of agricultural produce and help more new farmers succeed in business expansion.
\end{abstract}

Keywords- agricultural produce, e-Business, brand building

On 2015's NPC and CPPCC sessions, Premier LI KEQIANG proposed the strategy of "mass entrepreneurship and innovation" and the strategy of Internet +" in his government work report. Agriculture, as a pillar industry of China for a long time, has played a crucial role in China's economic development. The e-Commerce of agricultural produce since 2013 has shown a prairie fire, e-Commerce websites for various agricultural produces are surging and many categories of agricultural produces are hot sale online. Statistical data show that China had 649 million netizens, with the popularity rate as high as $47.9 \%$ in 2014 , including 557 million mobile netizens, representing $85.8 \%$; 178 million rural netizens, representing $27.5 \%$. With the increase of netizens in number, the Year 2014 witnessed the rapid development and booming trend of e-Commerce involving agriculture in China, where there are 31,000 agriculture-related e-Businesses, including approx. 4,000 trading ones.

With the rise of more and more new farmers, the popularity of internet and the rapid development of logistics industry, entrepreneurial farmers in rural China will also be closely integrated with Internet to seize the opportunity vested by this epoch wave for new great-leap-forward development.

Although the development of e-Commerce of agricultural produce is overwhelming, many new farmers are also desirous to succeed in business by virtue of e-Commerce of agricultural produce, once the e-Commerce is implemented, they will find it truly difficult to make profit in this regard. In the author's opinion, main reasons are centred on the followings: first, agricultural produces are difficult to be produced in such standardized, batched, regular and stabilized manner as industrial goods and they would be restricted by numerous natural conditions; secondly, different categories of agricultural produces need different warehousing and transporting conditions. In addition, e-Commerce's logistics operation of agricultural produces is of great difficulty and distribution cost remains high. Just the agricultural produces' own characteristics make e-Commerce of agricultural produce bustling in appearance, while genuinely many e-Commerce sellers of agricultural produce are difficult to make profit and difficult to achieve the desired effect of driving farmers' entrepreneurship and increasing their revenue.

On one hand, more and more companies and individuals are joining the family of e-Commerce of agricultural produce, competition of which is increasingly fierce, and as restricted by multiple environmental factors, only a small number of businesses can obtain sustainable competitive advantage and profitability in the industry and even a large number of them have been dismal and ended; on the other hand, with the constant improvement of consumers' spending power, consumers' demand for agricultural produces has undergone tremendous change, i.e. from the past pursuit of quantity to the present constant pursuit of high-quality produces. In the author's opinion, to make agricultural produces stride forward from traditional distribution channel to e-Commerce and to obtain sustainable profitability in the competitive market, the business need high-quality produce and a sophisticated service system, of which the most important is to make greater effort to build e-Commerce brand of agricultural produce, because only building e-Commerce brand of agricultural produce can help solve the problem of "sale difficulty and low price of selling" in e-Commerce and the brand is also a symbol of high quality, high grade and high status.

In the author's opinion, building e-Commerce brand of agricultural produce should be commenced from the following fields:

\section{ESTABLISH BRAND AWARENESS AND MAINTAIN MARKET POSITIONING}

It is equally important for e-Commerce businesses of agricultural produce to establish brand awareness. Building a good e-Commerce brand of agricultural produce can help e-Commerce businesses reduce cost for sales promotion; "packing" and presenting information on agribusiness and product with brand to consumers can yield twice the result with half the effort so as to achieve the goal of reducing marketing cost and increasing sale.

Taking "Western Farm Beauty" as an example, this 
e-Business's start-up capital was only RMB 5,000 in incorporation, while her annual sale in 2015 amounted to nearly RMB 300 million, the important thing behind this success is maintaining good market positioning for her produce through creating a good brand. "Western Farm Beauty" is a brand name with geographical characteristic and would be naturally reminiscent of produces with western characteristics, e.g. HOTAN Jujube and XINJIANG raisins. While marketing agricultural produces with Western characteristics, "Western Farm Beauty" is oriented to selection of optimal categories, such as best jujube and best raisins all the time for sale online, and persisting in profiting with high sales volume at the low price and giving up high profit; enhancing her brand through high quality of catchpenny produces.

\section{II.CAPTURE USER GROUPS AND DESIGN GOOD BRAND IMAGE}

Successful companies usually have a perfect brand image system, which is also an expression of their corporate characteristics and personality, so capturing user groups and good design of brand imagine can help users deepen their understanding on the enterprise's product in a short term and render this understanding into effective purchasing power. Some companies also continue to update their image to meet their present demand, thus it can be seen that a brand image with vitality is of significance of the enterprise.

Of numerous Internet e-Commerce brands of agricultural produce, quite a few have precisely captured the targeted user groups through good design of brand image. Taking "Three Squirrels" as an example, this e-Business earned RMB billions just within a couple of years of revenue and created a miracle in Chinese history of e-Commerce. As an Internet brand of nut, her produce quality itself is not very different from that of other producers; while "Three Squirrels" has built her brand differentiation as the greatest connotation, infused corporate culture into her brand image and perfected her user experience. "Three Squirrels" has targeted the youth group below 35 as her major consumer group. "Three Squirrels" took three squirrels in cartoon image as her brand image representative, which are lovely and vivid in shape, bright and shining in colour, and named "XIAOJIAN" "XIAOKU" and "XIAOMEI" respectively. Through personalized moulding of three anthropomorphic squirrels, each of which is endowed with distinct representation to attract consumers' attention, "Three Squirrels" strengthened her corporate brand positioning.

\section{FOCUS ON USERS' EMOTIONAL EXPERIENCE AND GOOD BRAND COMMUNICATION}

Both traditional industries and e-Commerce businesses attach great importance to the study on users' experience. For e-Commerce companies, good user experience is an important factor for corporate brand image building. In the author's opinion, e-Commerce brand of agricultural produce can do a good job of users' emotional experience and brand communication from the followings:

\section{A. Legible Website Information, Attractive Interface Design And Easy Navigation Design}

As an e-Commerce brand, legible website information, attractive interface design and easy navigation design have gradually become the key to whether the brand has loyal customers and all of them are devised on the basis of users' experience. Good design of users' experience can retain customers, increase conversion ratio, and quickly allow users to achieve their operational objectives, what's more, make operational interaction more pleasant and effective, and interactive experience relation between the produce and the user increasingly close.

\section{B. Let Consumers Experience Close to The Nature}

The e-Commerce users' experience of agricultural produce is different from that of electrical appliances, clothing or the like; the most important in the e-Commerce users' experience of agricultural produce is to let users experience close to the nature. on one hand, the e-Businesses of agricultural produce can allow consumers to experience the feeling of field through beautiful pictures; on the other hand, their farm can publish on their website information on field visit, learning farm and agricultural festivals and the like event so that consumers can participate in agricultural practice, experience the joy of being close to the nature, and above all, consumers can have more confidence in the farm and believe the safe reliability of agricultural produce through participation in labour practice.

\section{Gradually Realize Scaled and Standardized Production \\ Of Agricultural Produce, and Improve Satisfaction of Shopping Experience}

Quite a few consumers shopping agricultural produce online usually have such experience: the produce bought today is delicious while those procured on another day would not be the same, because they would be unlikely to procure what grew in the same village. The main reason for this is fragmented agricultural operation. China's agricultural produces derive from decentralized operation by every single household, lacking of effective organization and strong driving effect by leading enterprises. This inevitably has randomness on specific production process and the quality of produce is difficult to be effectively controlled, as a result, consumers are hard to accurately grasp the brand identity and accordingly their confidence in the brand of agricultural produce is substantially reduced. Therefore, to develop e-Commerce brand of agricultural produce, the business need to realize scaled and standardized production through integration of sourcing bases and improve customers' satisfaction in shopping experience, and this is also an important means for e-Commerce businesses of agricultural produce to reduce cost, reduce waste and make profit.

\section{Safeguard Consumers and Achieve Sustained Growth}

Conventional e-Commerce of agricultural produce has brand building reposed improving pure flow to promote transaction through flow conversion, such form is very simple, not only the cost of advertising is prohibitively high 
and customers are difficult to be retained for a long time. Consumers, to buy agricultural produces online, need more comprehensive knowledge on such brand, including the concept, team, procurement and production process and so on for the reason of distance, thus increased understanding on such brand will promote users' continuous purchase. Maintenance of e-Commerce produce brand consumers can interact with consumers on a regular basis by means of microblog and WeChat and give full play to consumers' experience. Allowing consumers' full participation can meet both the demand of emotional exchange with consumers and the need of the business in information collection and feedback, and consumers should also be allowed to have the experience of "gaining initiative" and truly to be part of such brand building, communication and maintenance. Future e-Commerce of produce need to foster a loyal fan base of food, to hitch up one person to tie down his/her peers and give a full play to the commercial value of fan economy.

\section{IMPROVE BRAND SATISFACTION IN COMBINATION WITH MODERN LOGISTICS AND NEW MODEL}

Since agricultural produce has distinct seasonal and regional characteristics, and liable to rotting and deterioration in transit, e-Commerce produce brand building should also make use of existing advanced logistics distribution system, for example, for fresh produce, "the last kilometre" of distribution should be contracted to a professional third-party cold-chain logistics business so as to minimize the wastage of produce through cold-chain distribution. In addition, with the addition of new business model, such as "e-Commerce + Express Logistics of Cold Chain + Intelligent Terminal Pickup", a good result has been achieved in e-Commerce marketing of agricultural produce in many cities, and connection with this new model can better improve consumers' satisfaction with e-Commerce produce brand.

\section{REFERENCES}

[1] LI JUNBO and CHEN MIN: Problems and Innovative Countermeasures in the Development of e-Commerce of Agricultural Produce in Commercial Times [J].2014.12.

[2] LU JIANG, JIN XIAOHONG, GAOJIE and CHAIPAN FENG: Study on Brand Building of Aquatic Product e-Commerce - Taking LIANGZI Lake Crab as an example in ANHUI Agricultural Sciences [J]. 2015.20.

[3] ZHOU YINGLAO: Three Squirrels beyond Expectations in Business Management [J].2014. (4):52.

[4] YILIN, LIU HANWEN and HUANG WENYU: e-Commerce Brand Communication Seen from the Case of Three Squirrels in Market Modernization [J]. 2015.7. 